\title{
The origins, development, and context of the Lancet Commission on the Value of Death
}

\author{
Richard Smith chair UK Health Alliance on Climate Change
}

Yesterday saw the publication of the Lancet Commission on the Value of Death: Bringing Death Back Into Life. ${ }^{1}$ Today there was a launch webinar, which you will be able to watch even if you are reading this months later. There will also be a podcast and a video, which you can access. I was one of the founder members of the commission four years ago and want to provide some insights into the origins, development, and context of the report. (This piece is closely related to a short piece I have recorded for the webinar.)

I hope that many people will read the report, provide feedback, and most importantly help implement its recommendations. The report is some 30 ooo words long and, I must confess, a complex document, although I hope easily read. Indeed, I think that reading it can be enjoyable. There is an executive summary, but much will be missed by those who read only the summary.

Our starting point was that many societies and health systems have developed an unhealthy relationship with death and dying. We know that many people in, for example, Britain die badly, often in acute hospitals or nursing homes-despite Britain twice ranking first in league tables of the best place to die. There is often excessive treatment at the end of life, increasing not reducing suffering. Conversations about dying that should happen don't happen. Death has turned from being a family, social, and cultural event to primarily a medical event. Health professionals have become the custodians of death. Death is not taboo (during the pandemic we have heard about it all the time, and tragedies are measured in numbers of deaths), but it is hidden. Most people are unfamiliar with death and dying, probably increasing the fear of dying and death.

Interestingly, and perhaps surprisingly, we found almost universal agreement about our propositions, including from families, patients, citizens, and health professionals of many types.

The title of the Commission, the Value of Death, came about because the Lancet has also been planning a Lancet Commission on the Value of Life. The choice reflected the importance of death and dying within life and living, and the slightly strange title proved a rich source of reflection. The familiar saying that "Without death every birth would be a tragedy" is one part of the value of death-and particularly relevant on a planet that is struggling to support its population. We all die and that we do so, some philosophers argue, is the most important thing about us: that we all die binds us together, as the medieval pictures showing the deaths of emperors, peasants, physicians, and others reminds us. Another value of death is that being with and caring for the dying is often seen as a gift, as Gandhi in his autobiography and many others have described. For some, including me, death also provides a narrative, even a meaning, to life. I am on the decline and would not want to be young again.

Because we wanted to avoid a purely medical view of death and dying, we assembled a group of Commissioners including a wide range of people: social scientists, a philosopher, religious leaders, an author, journalists, and health professionals, including an oncologist, nurse, GP, surgeon, public health, and palliative care physicians. A central idea was that death and dying belong to everybody, not just to health professionals and palliative care physicians, a specialty that is sometimes seen as "owning death."

Several of the commissioners are from low and middle income countries, and the Lancet Commission on Palliative Care and the Relief of Suffering has already shown that most people in the world have little or no access to even minimal treatment, including opioids, at the end of life. To die in pain without access to opioids has been described as torture. But we also realised that overtreatment occurs in low and middle income countries (and there is some evidence in the report that it may be worse in those countries) and is a common cause of families falling into poverty.

The overall picture is of excessive treatment for some, mostly in high income countries, and inadequate treatment in most poorer countries.

Our thinking evolved in leaps as we worked, and certain ideas were very important. I want to briefly describe five.

The sociologist Lyn Lofland's book The Craft of Dying helped us understand how death has changed since the 1950 shen the medical aspects of death and dying were not so dominant. ${ }^{2}$ People are older when they die, death is slower, the technology to fend off death has increased dramatically, death is more often in institutions (hospitals and care homes), and the "meaning" of death and dying, which was largely supplied by religion, has fallen instead to the health system, which cannot supply meaning.

Perhaps our most important recognition was that there is "a death system"--that there are a great many factors that influence death and dying: cultural, social, community, political, economic, technological, philosophical, and clinical. Attempts to make changes that do not recognise the complexity of the system are likely to fail and lead to unintended consequences. But systems do change (as I've described in the paragraph above), and the report describes the potentially most powerful ways to change the system, rebalancing it. 
Clearly not everybody in the Commission agreed about everything, and our report includes a figure showing the extent of agreement with several statements-for example, support for assisted dying, where we knew there would be disagreement. We had intense discussions when we met and thought there might be considerable disagreement; but there was actually high agreement with most statements. I came to think that every report written by a group of people ought to include such a figure.

Recognising the impossibility of knowing the future, we produced five scenarios, bold but plausible futures. One was health systems being overwhelmed with the number of deaths (which happened in many countries during the pandemic), and another was assisted dying becoming a much commoner mode of death than now.

Our fifth leap was to include a realistic utopia of how we would like death and dying to be. The idea of a realistic utopia, one that is radically different from now, but achievable, was proposed by the philosopher John Rawls. We present the principles of our realistic utopia in the report, but in essence they involve bringing death back into life, recognising the value of death, and rebalancing care of the dying among health professionals, families, and communities, making it more of a partnership.

Importantly something not far removed from our realistic utopia already exists - in Kerala, India-as is described in some detail in the report. We also describe how ideas developed in Kerala are spreading.

Our work began some two years before the pandemic, and by coincidence we had a meeting just as deaths from Covid began to steeply rise in Europe. For a moment we thought that we might have to abandon a report with a title of the value of death, but we quickly reached the opposite conclusion-that if a world closer to what we advocate, with much more involvement of families and communities, existed then countries would be much more able to cope.

We also realised that the pandemic, excessive treatment at the end of life, and attempts to defeat death (we describe in the report the big investments being made to greatly lengthen life, even achieve immortality) have common roots-the delusion that we are masters not part of nature. We recognised as well that the climate and ecological crisis, the existential threat of our time, also has the same root cause, the delusion of being masters of nature. This was an important development in our thinking.

If we are to avoid the catastrophe to health of global temperatures rising by more than $1.5 \mathrm{C}$ above pre industrial levels then all activities, including health care, will have to reach net-zero by 2040. Health systems are major emitters of greenhouse gases: if health systems were a country they would be the fifth biggest emitter of greenhouse gases.

Our report finds that something above $10 \%$ of health care expenditure is on people who die in that year-and cost and emissions of greenhouse gases go closely together. There is an ecological as well as health reason for changing how we die.

We need to think again about what health systems and health research are for-are they about defeating death, which they often seem to be, or should they be about reducing suffering and maintaining our humanity? Perhaps our health and research systems are as out of control as our economic and business systems.

On that uncomfortable thought, I thank the Commissioners, others who contributed to the report, and the Lancet team and hope you will read our report carefully and contribute to the change that needs to happen.

Competing interest: RS was one of the founders of the Commission and a co chair. He received no payment for the four years of work, although the Commission did meet in Bellagio, Italy, funded by the Rockefeller Foundation and had a grant from the four British universities of the South West. RS paid his own way to all the meetings, but did enjoy the excellent hospitality in Italy without paying more than his fare there.

Sallnow L, Smith R, Ahmedzai SH, etal. Report of the Lancet Commission on the Value of Death: bringing death back into life. Lancet 2022;•••. doi: 10.1016/S0140-6736(21)02314-X.

2 Smith R. The struggle to create a new craft of dying. What is medicine's role. December 2019. BMJ Opinion. https://blogs.bmi.com/bmi/2019/12/18/richard-smith-the-struggle-to-create-a-newcraft-of-dying-what-is-medicines-role/ 